F. Reprod. Fert. (1968) 16, 119-120

\title{
A CASE OF XXY SEX CHROMOSOME CONSTITUTION IN AN INTERSEX PIG
}

\author{
A. J. BREEUWSMA* \\ Research Institute for Animal Husbandry, Schoonoord, Zeist, The Netherlands
}

(Received 28th December 1967)

In recent years several reports on the genetic characteristics of intersexes in pigs have been published (Johnston, Zeller \& Cantwell, 1958; Makino, Sasaki, Sofuni \& Ishikawa, 1962; Gerneke, 1964; Hard \& Eisen, 1965; Vogt, 1966; McFee, Knight \& Banner, 1966). All the reported cases were found to be genetically female; only one pig was reported to have an $\mathrm{XX} / \mathrm{XY}$ sex chromosome mosaicism (McFee et al., 1966). This communication deals with a case of porcine XXY sex chromosome complement.

The pig described here was of the Dutch Landrace $(120 \mathrm{~kg})$ and had mainly male characteristics, i.e. a small penis (Pl. 1, Fig. 1) and a unilateral scrotal hernia. In order to determine the genetic sex of this animal examination of the nuclear sex and chromosome analysis was carried out.

For the demonstration of sex chromatin, sections of the spinal cord were made and stained with the Feulgen technique. Over $90 \%$ of the examined neurons showed the presence of a sex chromatin body (PI. 1, Fig. 2). This finding agrees with those of Cantwell, Johnston \& Zeller (1958) and Barr (1963).

Chromosome analysis was carried out with the method described by Arakaki \& Sparkes (1963) which is a modification of the original technique of Moorhead, Nowell, Mellman, Battips \& Hungerford (1960). A total of thirty-two metaphase spreads were examined of which thirty possessed thirty-nine chromosomes. According to Ruddle (1961), Makino et al. (1962), GimenezMartin, Lopez-Saez \& Monge (1962) and McConnell, Fechheimer \& Gilmore (1963) the normal domestic swine has thirty-eight chromosomes.

The demonstration of sex chromatin signifies the presence of at least two $\mathrm{X}$ chromosomes, and in addition to the data on metaphase chromosomes the presence of an XXY chromosome complement may be concluded, as the $\mathrm{Y}$ chromosome is easily identifiable. Examples of an XXY karyotype and a normal male karyotype are illustrated in Pl. 2, Figs. 1 and 2.

After slaughtering the animal, the genital organs were excised for anatomical examination. The genital tract consisted of a uterus-like organ with two small testes (178 g). The histological picture showed some evidence of Sertoli cells in the seminiferous tubules. No spermatogenesis existed. The body of the uterus ended in a short urethra with a small penis $(3 \mathrm{~cm})$. There were very poorly developed seminal vesicles.

Although it had almost become accepted that porcine intersexes were always genetically female, this first finding of an XXY sex chromosome complex in a

* Present address: Veterinary Research Laboratory, Kabete, Kenya. 
farm animal confirms the assumption that some porcine intersexes are analogous to Klinefelter's syndrome in humans.

More studies on intersexuality in pigs are currently being conducted and will be reported at a later date.

I wish to thank $\mathrm{Mr} \mathrm{H}$. van der Veen for his assistance in determining the genetic sex and Dr W. Sybesma for his advice.

\section{REFERENCES}

Arakaki, D. T. \& Sparkes, R. S. (1963) Microtechnique for culturing leukocytes from whole blood. Cytogenetics, 2, 57.

BARR, M. L. (1963) The sex chromatin. In: Intersexuality, p. 48. Ed. C. Overzier. Academic Press, New York.

Cantwell, G. E., Johnston, E. F. \& Zeller, J. H. (1958) The sex chromatin of swine intersexes. 7. Hered. 49, 199.

Gerneke, W. H. (1964) The karyotype of a gonadal male pig intersex. S. Afr. J. Sci. 69, 347.

Gimenez-Martin, G., Lopez-Saez, J. F. \& Monge, E. G. (1962) Somatic chromosomes of the pig. 7. Hered. 53, 281.

HaRd, W. L. \& EISEN, J. D. (1965) A phenotypic male swine with a female karyotype. F. Hered. $56,255$.

Johnston, E. F., Zeller, J. H. \& Cantwell, G. (1958) Sex anomalies in swine. F. Hered. 49, 255.

Makino, S., Sasaki, S., SorunI, T. \& Ishikawa, T. (1962) Chromosome condition of an intersex swine. Proc. Japan Acad. 38, 686.

MaConneli, J., Fechirimer, N. S. \& Gilmore, L. O. (1963) Somatic chromosomes of the domestic pig. F. Anim. Sci. 22, 374.

MaFee, A. F., KNIGHT, M. \& BANner, M. W. (1966) An intersex pig with XX/XY leucocyte mosaicism. Can. F. Genet. Cytol. 8, 502.

Moorhead, P. S., Nowell, P. C., Mellman, W. J., Battips, D. M. \& Hungerford, D. A. (1960) Chromosome preparations of leucocytes cultured from human peripheral blood. Expl Cell Res. 20, 613 .

Rudde, F. H. (1961) Chromosome variation in cell populations derived from pig kidney. Cancer Res. $21,885$.

VoGt, D. W. (1966) Cytological observations on an intersex pig. F. Anim. Sci. 25, 252. 


\section{PLATE 1}

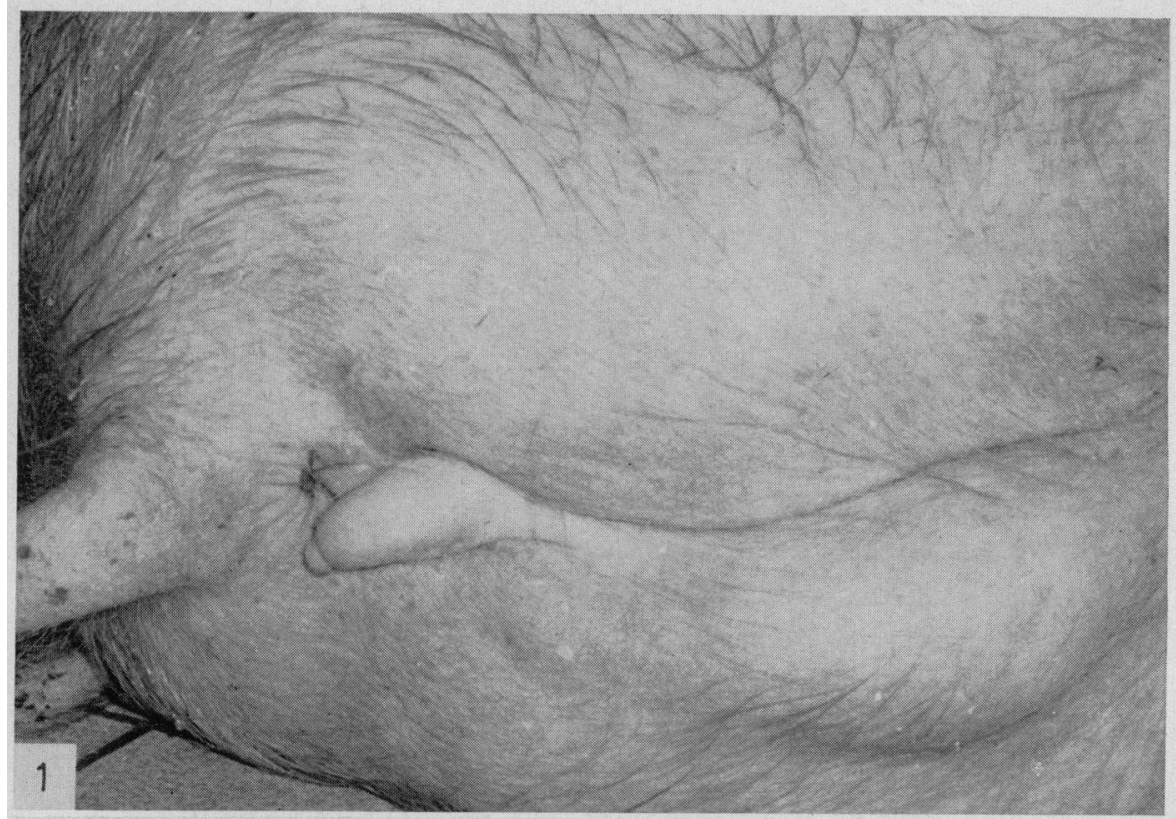

2

Fig. 1. A small penis $(3 \mathrm{~cm})$ and a hernia scrotalis in an intersex pig.

FIG. 2. Neuron of an intersex pig showing a sex chromatin body. Feulgen, $\times 1000$.

(Facing p. 120) 


\section{PLATE 2}

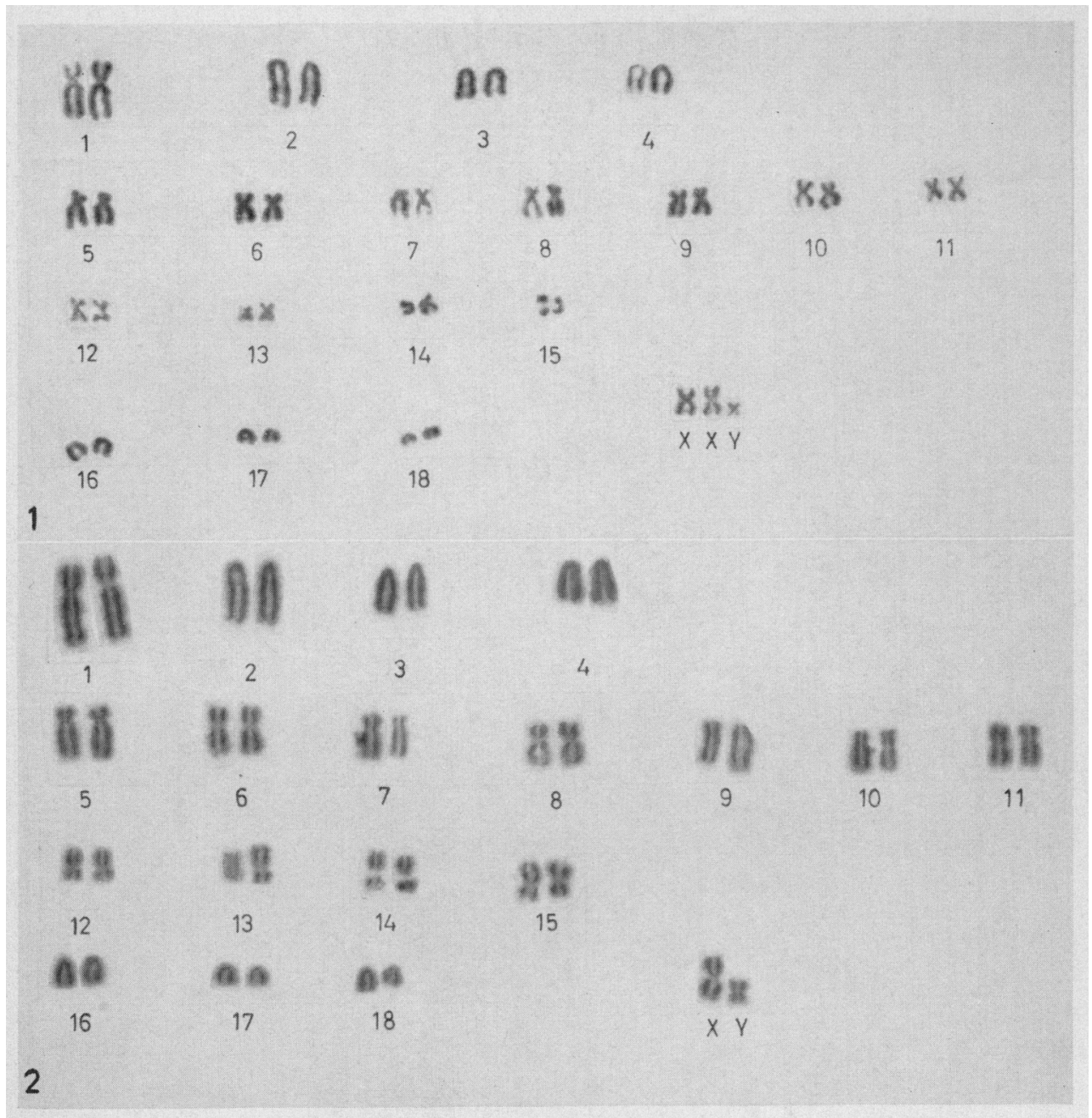

Fig. 1. Karyotype from an intersex pig showing an XXY sex chromosome complex.

Fig. 2. Karyotype from a normal male pig for comparison. 